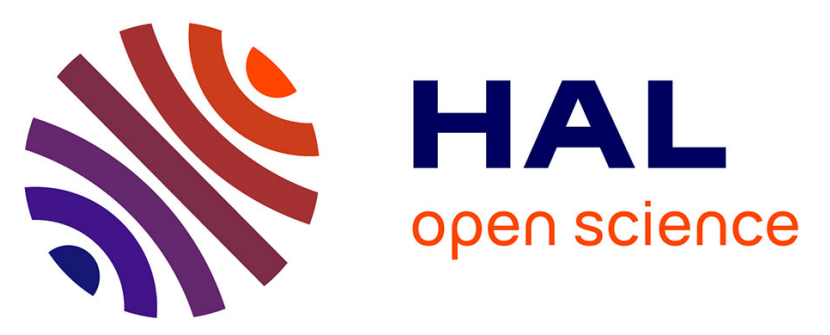

\title{
Bubble rising velocity and bubble size distribution in columns at high pressure and temperature: From lab scale experiments to design parameters
}

Clément Leonard, Jean-Henry Ferrasse, Sébastien Lefevre, Alain Viand, Olivier Boutin

\section{To cite this version:}

Clément Leonard, Jean-Henry Ferrasse, Sébastien Lefevre, Alain Viand, Olivier Boutin. Bubble rising velocity and bubble size distribution in columns at high pressure and temperature: From lab scale experiments to design parameters. Chemical Engineering Research and Design, 2021, 173, pp.108-118. 10.1016/j.cherd.2021.07.003 . hal-03597596

\section{HAL Id: hal-03597596 \\ https://hal.science/hal-03597596}

Submitted on 4 Mar 2022

HAL is a multi-disciplinary open access archive for the deposit and dissemination of scientific research documents, whether they are published or not. The documents may come from teaching and research institutions in France or abroad, or from public or private research centers.
L'archive ouverte pluridisciplinaire HAL, est destinée au dépôt et à la diffusion de documents scientifiques de niveau recherche, publiés ou non, émanant des établissements d'enseignement et de recherche français ou étrangers, des laboratoires publics ou privés.

\section{(1) (1) $\$$}

Distributed under a Creative Commons Attribution - NonCommercial - NoDerivatives| 4.0 


\title{
Bubble rising velocity and bubble size distribution in columns at high pressure and temperature: From lab scale experiments to design parameters
}

\author{
Clément Leonard ${ }^{a, b}$, Jean-Henry Ferrasse ${ }^{a}$, Sébastien Lefeure ${ }^{b}$, \\ Alain Viand ${ }^{b}$, Olivier Boutin ${ }^{a, *}$ \\ a Aix Marseille Univ, CNRS, Centrale Marseille, M2P2, Marseille, France \\ b S.A.R.L. A3i, 255 rue Gustave Eiffel, ZAC des Eoliennes, 26290 Donzère, France
}

\section{A R T I C L E I N F O}

\section{Article history:}

Received 17 February 2021

Received in revised form 2 July 2021

Accepted 5 July 2021

Available online 10 July 2021

\section{Keywords:}

Wet air oxidation

Bubble column design

Bubble rising velocity correlations

\begin{abstract}
A B S T R A C T
The design of bubble column for industrial applications is well known under near ambient pressure and temperature conditions, contrary to high pressure and temperature conditions. Accurate data on the evolution and behaviour of the bubbles is proposed as a basis for the evaluation of the surface area developed in the column and further design of such reactor. Two columns are used for the experiments: a small column $(8 \mathrm{~mL})$ with a total visualisation of the flow, and a bigger one $(1 \mathrm{~L})$, necessary for the scale up. Main results show that the influence of pressure and temperature are significant on the behaviour of bubbles and bubble size distribution and must be characterized and considered for the design of the columns in such conditions. The results allow the determination of two correlations: one for the bubble diameter and the other one for the bubble rise velocity, considering different parameters, and especially the superficial gas velocity in saturated conditions. These correlations are a basis to determine mass transfer correlations for the design of bubble column at high pressure and temperature conditions.
\end{abstract}

1. Introduction

Bubble columns are designed for many widespread industrial applications (Kantarci et al., 2005). Their operation is widely documented under near ambient pressure and temperature conditions, contrary to high pressure (higher than $5 \mathrm{MPa}$ ) and temperature conditions (higher than $150^{\circ} \mathrm{C}$ ) even if there are also many applications (for example the wet air oxidation treatment of aqueous waste) (Lin et al., 1998; Schäfer et al., 2002; Behkish et al., 2007; Oyevaar et al., 1991). It is therefore relevant to acquire data, and to derive parameters for the design of these columns in such high conditions. Therefore, research to obtain accurate data on the evolution and behaviour of the bubbles is of high importance, as it can serve as a basis for the evaluation of the interfacial area developed in the column and further design of such reactor. Indeed, at these high conditions of pressure and temperature, the characteristic time of oxidation kinetics is usually low. In these conditions, the characteristic time of oxygen mass transfer is higher, this phenomenon is hence the limiting factor. Therefore, the accurate determination of interfacial area is of high importance for the design of the bubble column, as a unit operation of gas liquid transfer. The interfacial area depends on bubble size distribution.

\subsection{Parameters influencing the bubble diameter and their rising velocity}

It is generally accepted that the hydrodynamics of the bubble columns can be divided into three different regimes (Schäfer et al., 2002; Behkish et al., 2007; Oyevaar et al., 1991):

- The homogeneous regime observed mainly at low superficial gas velocities, characterised by a narrow bubble size distribution.

- The heterogeneous regime observed at high superficial gas velocities and characterised by a large distribution of the bubble diameters.

\footnotetext{
* Corresponding author at: M2P2, Europôle de l'Arbois, BP 80, 13545 Aix en Provence Cedex 4, France.

E-mail address: olivier.boutin@univ-amu.fr (O. Boutin).
} 


\begin{tabular}{|c|c|}
\hline \multicolumn{2}{|c|}{ Nomenclature } \\
\hline$a_{\text {ell }}$ & Major axis of the ellipse $(\mathrm{m})$ \\
\hline$b_{\text {ell }}$ & Minor axis of the ellipse (m) \\
\hline$d_{B}$ & Bubble diameter $(\mathrm{m})$ \\
\hline$d_{B S}$ & Sauter diameter $(\mathrm{m})$ \\
\hline$d_{B, i}$ & Bubble i diameter $(\mathrm{m})$ \\
\hline$d_{B i, \max }$ & Maximum bubble diameter $(\mathrm{m})$ \\
\hline$d_{B i, \min }$ & Minimum bubble diameter $(\mathrm{m})$ \\
\hline $\mathrm{D}_{\mathrm{C}}$ & Capillary diameter (m) \\
\hline E & Acceleration factor (double film theory) (-) \\
\hline$\varepsilon_{\mathrm{G}}$ & Gas hold up (-) \\
\hline g & Gravity constant $\left(\mathrm{m} \mathrm{s}^{-2}\right)$ \\
\hline $\mathcal{L}_{d}$ & Width of the size distribution (m) \\
\hline $\mathrm{n}_{\text {bubble }}$ & $\begin{array}{l}\text { Number of bubbles used for bubble size distri- } \\
\text { bution (-) }\end{array}$ \\
\hline $\mathcal{R}_{\mathrm{B}}$ & Ratio of bubble diameters for different $u_{G}(-)$ \\
\hline $\mathrm{u}_{\mathrm{B}}$ & Bubble rise velocity $\left(\mathrm{m} \mathrm{s}^{-1}\right)$ \\
\hline $\mathrm{u}_{\mathrm{B}, \mathrm{m}}$ & Average bubble rise velocity $\left(\mathrm{m} \mathrm{s}^{-1}\right)$ \\
\hline $\mathrm{u}_{\mathrm{B}, \mathrm{K}}$ & $\begin{array}{l}\text { Bubbles rise velocity for class } \mathrm{K} \text { (S: small/L: } \\
\text { large) }\left(\mathrm{m} \mathrm{s}^{-1}\right)\end{array}$ \\
\hline $\mathrm{u}_{\mathrm{B}, \infty}$ & Terminal bubble rise velocity $\left(\mathrm{m} \mathrm{s}^{-1}\right)$ \\
\hline$u_{\mathrm{L}}$ & Liquid superficial velocity $\left(\mathrm{m} \mathrm{s}^{-1}\right)$ \\
\hline $\mathrm{u}_{\mathrm{G}}$ & Gas superficial velocity $\left(\mathrm{m} \mathrm{s}^{-1}\right)$ \\
\hline $\mathrm{u}_{\mathrm{G}, \mathrm{sat}}$ & $\begin{array}{l}\text { Gas superficial velocity in saturation conditions } \\
\left(\mathrm{m} \mathrm{s}^{-1}\right)\end{array}$ \\
\hline $\mathrm{V}_{\mathrm{B}, \mathrm{K}}$ & Bubble volume for class $\mathrm{K}\left(\mathrm{m}^{3}\right)$ \\
\hline$r_{G}$ & Gas density $\left(\mathrm{kg} \mathrm{m}^{-3}\right)$ \\
\hline$r_{L}$ & Liquid density $\left(\mathrm{kg} \mathrm{m}^{-3}\right)$ \\
\hline $\mathrm{m}_{\mathrm{L}}$ & Liquid viscosity (Pa s) \\
\hline $\mathrm{s}_{\mathrm{L}}$ & Liquid surface tension $\left(\mathrm{N} \mathrm{m}^{-1}\right)$ \\
\hline $\mathrm{w}_{\mathrm{K}}$ & Number fraction for class $\mathrm{K}(-)$ \\
\hline$\varsigma_{\mathrm{K}}$ & Volume fraction for class $\mathrm{K}(-)$ \\
\hline $\mathrm{x}_{\mathrm{W}}$ & Mass fraction $(-)$ \\
\hline Mo & Morton number \\
\hline $\mathrm{Re}_{\mathrm{B}}$ & Bubble Reynolds number \\
\hline $\mathrm{Ta}$ & Takadi number \\
\hline $\mathrm{We}_{\mathrm{B}}$ & Bubble Weber number \\
\hline
\end{tabular}

- A transition regime between the two cited above.

The transition between the different regimes is governed mainly by the superficial gas velocity but pressure, temperature, gas sparger and column design are also reported to be relevant. As the mechanism governing the different regimes are different, the operating parameters, such as pressure or temperature, are suspected to have different effects depending on the hydrodynamic regime.

\subsubsection{Pressure}

A significant decrease in the bubble diameter is observed by increasing the pressure up to $5 \mathrm{MPa}$, with different types of gas spargers, at ambient temperature conditions and in homogeneous regime (Lin et al., 1998; Schäfer et al., 2002). This pressure effect can be linked to a decrease in the bubble diameter, by an effect on the breaking. On the other hand, a plateau is observed for pressures higher than $6 \mathrm{MPa}$, in a homogeneous regime (Behkish et al., 2007; Oyevaar et al., 1991). Other studies indicate a higher number of bubbles and a decrease in bubbles rise velocity with increasing pressure (Kang et al., 2000; Wilkinson and Van Dierendonck, 1990; Lin and Fan, 1999).

The effect of pressure can be related to several parameters. First, an increase in pressure leads to a small and not significant increase in viscosity and liquid density (Lin et al., 1998). This effect remains marginal. On the other hand, the existence of a plateau and the weaker effect of pressure in a homogeneous regime indicate that the influence

Table 1 - Summary of the influence of several

\section{parameters.}

\begin{tabular}{lll} 
Parameter & $\mathrm{d}_{\mathrm{B}}$ & $\mathrm{u}_{\mathrm{B}}$ \\
\hline Pressure & $\downarrow$ (plateau) & $\downarrow$ (plateau) \\
Temperature & $\downarrow$ & $\downarrow$ \\
& $\uparrow\left(\right.$ low $\mathrm{u}_{\mathrm{G}} /$ high $\left.\mu_{\mathrm{L}}\right)$ & $\uparrow\left(\right.$ low $\mathrm{u}_{\mathrm{G}} /$ high $\left.\mu_{\mathrm{L}}\right)$ \\
$\mathrm{u}_{\mathrm{G}}$ & $\uparrow$ & $\uparrow$ \\
$\mathrm{u}_{\mathrm{L}}$ & $=$ & $\uparrow\left(\mu_{\mathrm{L}}>1.1 \mathrm{~cm} \mathrm{~s}^{-1}\right)$ \\
& & $=\left(\mu_{\mathrm{L}} \leq 1.1 \mathrm{~cm} \mathrm{~s}^{-1} /\right.$ low $\left.\mu_{\mathrm{L}}\right)$
\end{tabular}

decreases as the bubble diameter decreases. The effect of pressure is therefore probably linked to an increase in the density of the gas. An increase in gas density results in a decrease in bubble rise velocity: retention is therefore higher for denser gases also observe that an increase in gas density with pressure leads to a decrease in bubble rise velocity, and therefore an increase in gas retention. (Dewes and Schumpe, 1997; Letzel et al., 1998).

\subsubsection{Temperature}

An increase in temperature generally results in a decrease of the bubble diameter and a narrow bubble size distribution (Lin et al., 1998; Hashemi et al., 2009; Wilkinson et al., 1992; Schäfer et al., 2002; Pohorecki et al., 2001; Sangnimnuan et al., 1984; Lorenz et al., 2005; Soong et al., 1997; Shah et al., 1982). Two opposite effects must be considered. Increasing temperature results in a decrease in the surface tension which decreases the drainage rate of the liquid film, the diameter of the primary bubble and the maximum bubble diameter. On the other hand, the liquid viscosity also decreases, causing a decrease in the diameter of the primary bubble. Therefore, the drainage rate of the film and the collision frequency increase, promoting coalescence. In most cases, the influence of the decrease of the liquid viscosity is predominant, promoting coalescence. The effects on the collision frequency and the rate of drainage of the film are then predominant compared to the effects on the contact time (Yang et al., 2001). Therefore, it is important that further correlations consider this potentially high effect of temperature.

\subsubsection{Superficial velocity of liquid $\left(u_{L}\right)$ and gas $\left(u_{G}\right)$}

The influence of $u_{\mathrm{L}}$ appears to be limited at atmospheric pressure. Its increase leads to a small increase in the bubble size by increasing the proportion of liquid in the column (Simonnet et al., 2007; Kumar et al., 2012a; Pjontek et al., 2014; Kumar et al., 2012b). For higher pressures, the increase in $u_{\mathrm{L}}$ has no influence on the bubble size but leads to an increase in the rising velocity (Simonnet et al., 2007). On the other hand, under a homogeneous regime, the mean diameter of the bubbles increases slightly with $\mathrm{u}_{\mathrm{G}}$ (up to the transition regime) (Kluytmans et al., 2003). At the transition, the mean diameter increases while in a heterogeneous regime the proportion of large bubbles increases and that of small ones remains constant (Fukuma et al., 1987; Lau et al., 2012; Ferreira et al., 2013; García-Abuín et al., 2010; Friedel, 1979).

\subsubsection{Gas sparger}

The gas sparger has a major influence between homogeneous and transitional regimes but has no effect in well-established homogeneous and heterogeneous regimes (Zahradník et al., 1997; Reilly et al., 1986; Ohki and Inoue, 1970). Generally, porous or membrane spargers allow to obtain tight size distributions (and therefore better stability of the homogeneous regime) than perforated spargers (Kantarci et al., 2005; Zahradník et al., 1997; Krishna and Ellenberger, 1996; Bouaifi et al., 2001). Moreover, increasing the number of holes by fixing their diameter, and therefore increasing the free area, influences the formation of bubbles if the holes are closed enough to provoke coalescence between two bubbles at two adjacent holes (Zahradník et al., 1997; Polli et al., 2002).

Table 1 summarizes the influence of the parameters on the diameter of the bubbles and their rising velocity. 


\subsubsection{Bubble diameter}

The first correlations have been developed for low pressure and temperature conditions (Fukuma et al., 1987; Majumder et al., 2006). Wilkinson et al. (1994) proposed a valid correlation at higher pressures, up to 2 $\mathrm{MPa}$, but at $25^{\circ} \mathrm{C}$ (Eq. (1)). There are no valid correlations at higher pressure and temperature conditions.

$\frac{\operatorname{gd}_{\mathrm{BS}}^{2} \rho_{\mathrm{L}}}{\sigma_{\mathrm{L}}}=8,8\left(\frac{\mathrm{u}_{\mathrm{G}} \mu_{\mathrm{L}}}{\sigma_{\mathrm{L}}}\right)^{-0,04}\left(\frac{\mathrm{g} \mu_{\mathrm{L}}^{4}}{\sigma_{\mathrm{L}}^{3} \rho_{\mathrm{L}}}\right)^{0,12}\left(\frac{\rho_{\mathrm{G}}}{\rho_{\mathrm{L}}}\right)^{-0,22}$

\subsubsection{Bubble rise velocity}

Regarding the bubble rise velocity, three correlations have been validated under pressure. The correlation of Mendelson (1967) (Brian et al., 1961), based on wave theory, has been modified by Rollbusch et al. (2015) incorporating a term of the difference between liquid and gas densities to account for the effect of pressure on the gas density (Eq. (2)). This equation is valid for pressures up to $19.4 \mathrm{MPa}$ and temperatures up to $78^{\circ} \mathrm{C}$ (Rollbusch et al., 2015).

$\mathrm{u}_{\mathrm{B}, \infty}=\sqrt{\frac{2 \sigma_{\mathrm{L}}}{\rho_{\mathrm{L}} \mathrm{d}_{\mathrm{B}}}+\left(\frac{\rho_{\mathrm{L}}-\rho_{\mathrm{G}}}{\rho_{\mathrm{L}}}\right) \frac{g \mathrm{gd}_{\mathrm{B}}}{2}}$

In order to take into account the ellipsoid shape of the bubbles, the correlation of Tomiyama et al. (2002) can be applied (Wellek et al., 1978) (Eq. (3)).

$$
\begin{aligned}
& u_{B}, \infty=\frac{\sin ^{-1} \sqrt{1-E^{2}}-E \sqrt{1-E^{2}}}{1-E^{2}} \\
& \sqrt{\frac{8 \sigma_{L}}{\rho_{\mathrm{L}} d_{B}} \xi E^{4 / 3}+\left(\frac{\rho_{\mathrm{L}}-\rho_{\mathrm{G}}}{\rho_{\mathrm{L}}}\right) \frac{g d_{\mathrm{B}}}{2} \frac{\xi \mathrm{E}^{2 / 3}}{1-\xi^{2} \mathrm{E}^{2}}}
\end{aligned}
$$

E and $\xi$ are form factors depending on the geometric parameters of the bubbles. For a flattened spheroid, the diameter measured on the vertical axis is distorted. The correlation of Tomiyama et al. (2002) gives good results over the whole range of bubble diameters. Finally, a more complex correlation proposed by Fan-Tsuchiya (1990) (Lin et al., 1998) is presented by Eq. (4).

$$
\left.\mathrm{u}_{\mathrm{B}, \infty}=\left(\frac{\mathrm{g} \sigma_{\mathrm{L}}}{\rho_{\mathrm{L}}}\right)^{1 / 4}\left[\begin{array}{l}
\left\{\frac{\mathrm{Mo}^{-\frac{1}{4}}}{\mathrm{C}_{2}}\left(\frac{\rho_{\mathrm{L}}-\rho_{\mathrm{G}}}{\rho_{\mathrm{L}}}\right)^{\frac{5}{4}} \mathrm{~d}_{\mathrm{B}}{ }^{2}\left(\frac{\mathrm{g} \rho_{\mathrm{L}}}{\sigma_{\mathrm{L}}}\right)\right\}^{-\mathrm{C}_{3}}\left(\frac{\mathrm{g} \rho_{\mathrm{L}}}{\sigma_{\mathrm{L}}}\right)^{-\frac{1}{2}} \\
+\left(\frac{\rho_{\mathrm{L}}-\rho_{\mathrm{G}}}{\rho_{\mathrm{L}}}\right) \frac{\mathrm{d}_{\mathrm{B}}}{2}\left(\frac{\mathrm{g} \rho_{\mathrm{L}}}{\sigma_{\mathrm{L}}}\right)^{1 / 2}
\end{array}\right\}^{-1 / \complement_{3} / 2}\right]^{-1 / C_{3}}
$$

$\mathrm{C}_{1}$ is a parameter considering the difference in surface tension for pure liquids (1.2) and mixtures (1.4). $\complement_{2}$ is given by Eq. 5 .

$$
\complement_{2}=\max \left(\complement_{4} \mathrm{Mo}^{-0.038} ; 12\right)
$$

$\complement_{3}$ considers the effect of contaminants (0.8 for contaminated liquids and 1.6 for pure liquids). $\complement_{4}$ depends on the nature of the liquid and is equal to 14.7 for aqueous solutions and 10.2 for pure or mixed organic solvents. The Fan-Tsuchiya equation is valid for $1 / \mathrm{Mo}<1012$. The best results are obtained in the entire range of bubble diameter, except at high temperature where a peak of the rising velocity can be observed in the range 1-3 mm (Rollbusch et al., 2015; Lin et al., 1998). The correlation of Tomiyama et al. (2002) can predict this maximum.

\subsection{Parameters tested in this study}

Some parameters must be carefully chosen for the design of the column. Results show that the height of dispersion has no influence for height/diameter ratios higher than 5 (Zahradník et al., 1997; Xue et al., 2008; Ruzicka et al., 2001; Wilkinson et al., 1992; Whalley and Hewitt, 1978). This ratio is verified for the columns used in this study. On the other hand, at a small column diameter, wall effects are likely to affect the maximum diameter of the bubbles, their rising velocity, and the recirculation of the liquid in heterogeneous conditions. Most authors consider that the column diameter has no influence for values higher than $0.15 \mathrm{~m}$, whether in well-established homogeneous or heterogeneous regimes (Kantarci et al., 2005; Wilkinson and Van Dierendonck, 1990; Tomiyama et al., 2002).

Considering previous results in the literature and previous correlations, four parameters will be tested in this study: pressure, temperature and superficial velocities of gas and liquid. To determine dimensioning correlations, the measurement of the bubble's properties (diameter and rising velocity) is undertaken in two bubble columns. The first is at laboratory scale in sapphire, allowing full visibility of the flows. The second is a $1 \mathrm{~L}$ stainless steel column used for scaling up and design purposes.

\section{Material and methods}

\subsection{Experimental devices}

\subsubsection{Sapphire bubble column}

The sapphire bubble column allows direct visualisation of the gas/liquid flow (Fig. 1, internal diameter $1 \mathrm{~cm}$, external diameter $2.4 \mathrm{~cm}$, height $10 \mathrm{~cm}$, volume $8 \mathrm{~mL}$, pressure up to $20 \mathrm{MPa}$ and temperature up to $200^{\circ} \mathrm{C}$ ). Temperatures are measured at the inlet and the outlet. To avoid wall effects as much as possible, the gas is injected into a central area (diameter $0.5 \mathrm{~cm}$ ). A piston pump (Top Industrie, France,jvolume $53 \mathrm{~mL}$ ), is used for liquids in the range of $1-5 \mathrm{~mL} \mathrm{~min}^{-1}$ ( $u_{\mathrm{L}}$ identical to those of the stainless steel column described below: $0.022-0.122 \mathrm{~cm}$ $\left.\mathrm{s}^{-1}\right)$. Flow rates accuracy is $0.3 \%$ (Lefèvre et al., 2011). The gas is pumped from a bottle ( $25 \mathrm{MPa}$, Air Liquide) by two piston pumps (Top Industrie, France) one for $\mathrm{u}_{\mathrm{G}}=0.022-0.396 \mathrm{~cm} \mathrm{~s}^{-1}$ and the other for $\mathrm{u}_{\mathrm{G}}=0.4-1.6 \mathrm{~cm} \mathrm{~s}^{-1}$. Fluids are heated with a tubular heat exchanger. Column and exchangers are placed in an oven. The use of porous material with an average pore diameter of less than $100-200 \mu \mathrm{m}$ is recommended for good performance. The sparger installed on the column is a PORAL ${ }^{\circledR}$ type fritted system with an average pore diameter of $80 \mu \mathrm{m}$.

The camera used for the measurements is a Canon EOS M ${ }^{\circledR}$ with 19 MPixel resolution and a $60 \mathrm{~mm}$ fixed-aperture macro lens (f/2.8). The camera can shoot videos at a maximum shutter speed of 50 frames/second. The accuracy on the diameter (2 pixels) using a photo is $\pm 28 \mu \mathrm{m}$.

\subsubsection{Stainless steel column $1 \mathrm{~L}$}

For design and scale up purposes, a $1 \mathrm{~L}$ stainless steel column is used (internal diameter $4 \mathrm{~cm}$, height $83 \mathrm{~cm}$, Inconel $625,30 \mathrm{MPa}, 350^{\circ} \mathrm{C}$ ). This column is fully described in Léonard et al. (Leonard et al., 2019). It is equipped with an outlet pressure sensor. It is divided into three stages heated by an electric collar (first stage) or a heat-exchange double jacket (2nd and 3rd stages). These systems allow a good constant temperature control. After cooling, a Tescom ${ }^{\circledR}$ back pressure regulator is used to control the pressure. Gas is admitted into a pneumatic 


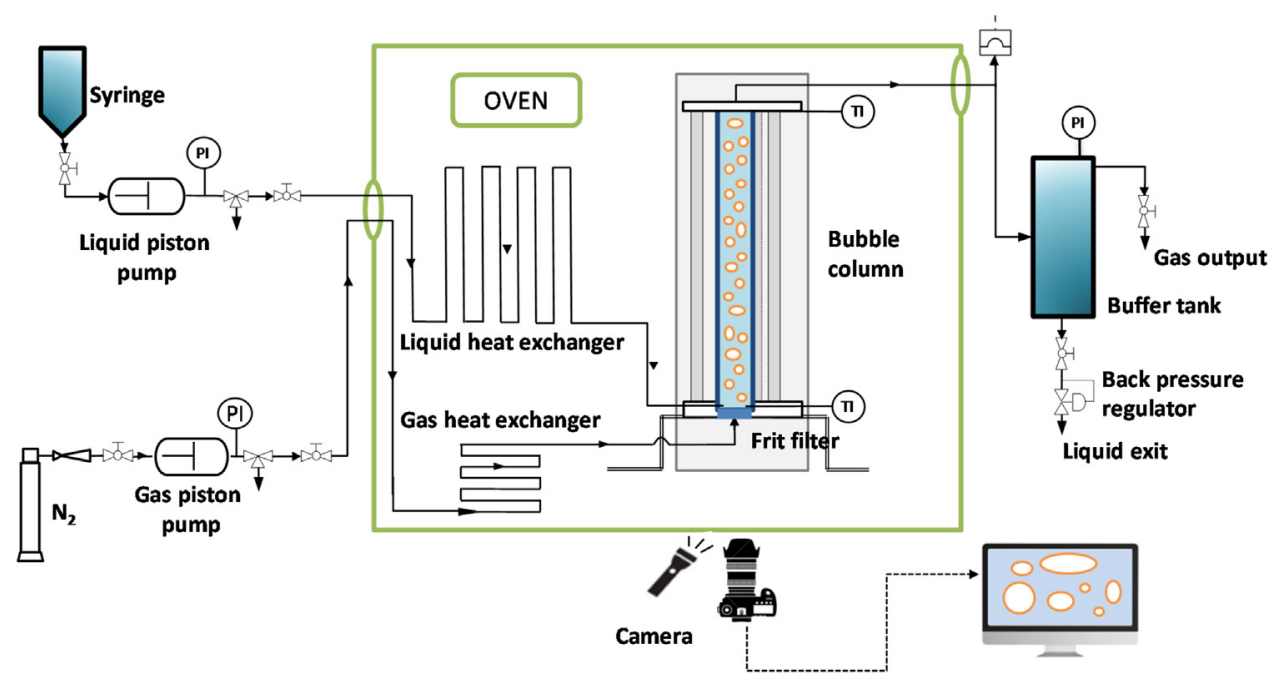

Fig. 1 - Sapphire column.

booster system (DLE-75-1, Maximator), measured by a mass flow meter (Bronkhorst El-FlowF232-M 0-65 NL min ${ }^{-1}$, accuracy: $\left.\pm 0.065 \mathrm{~N} \mathrm{~L} \mathrm{~min}^{-1}\right)$. The gas is heated in a heat exchanger (1500 W electric heating collar). The gas is injected using a porous medium with an average pore diameter of $80 \mu \mathrm{m}$ (the same as the sapphire column). At $10 \mathrm{MPa}$, the superficial velocity range is $0.20-1.70 \mathrm{~cm} \mathrm{~s}^{-1}\left(0.1-0.88 \mathrm{~cm} \mathrm{~s}^{-1}\right.$ at $20 \mathrm{MPa}$ and $0.08-0.65 \mathrm{~cm} \mathrm{~s}^{-1}$ at $30 \mathrm{MPa}$ ). The liquid pump is a piston pump (Separex LGP50, France) with flowrates from 0 to $120 \mathrm{~g} \mathrm{~min}^{-1}$, up to $100 \mathrm{MPa}$. The superficial liquid velocity is in the range $0.04-0.16 \mathrm{~cm} \mathrm{~s}^{-1}$.

\subsection{Measurement of bubble size distribution}

The thickness of the sapphire and the curvature being important, the diameters measured in photos must be adjusted. The deformation of 8 glass balls with diameters between 0.6 and $6.4 \mathrm{~mm}$ is quantified using deformation coefficients, defined as the ratio of the deformed diameter to the actual diameter, and used for bubble size measurements. This deformation coefficient varies between 1.197 in the centre of the column and 1.459 on the sides. The column is divided into 5 floors with $2 \mathrm{~cm}$ steps. The 0 is at the gas sparger in the injection zone. The average diameter of the bubbles is determined in each stage, in the entire column and in the zone corresponding to height/diameter $>5$ to be in a zone without the influence of the gas sparger (last 2 stages). The bubbles are considered ellipsoidal. Under these conditions, the minor and major axes of the ellipse are manually measured from the pictures using GIMP $^{\circledR}$ software. The diameter of the sphere of the same volume is then evaluated with Eq. (6).

$\mathrm{d}_{\mathrm{B}, \mathrm{i}}=\left(\mathrm{a}_{\mathrm{ell}}^{2} \mathrm{~b}_{\mathrm{ell}}\right)^{1 / 3}$

The error on the diameter is determined by an error propagation law from the measurement of the diameters of the axes (2 pixels) and the deformation coefficient. It is between 0.9 and $9.1 \%$. The error is less than $3 \%$ for bubbles larger than
$0.4 \mathrm{~mm}$ in diameter. Sauter's mean diameter is then evaluated with Eq. (7).

$\mathrm{d}_{\mathrm{BS}}=\frac{\sum_{\mathrm{i}} \mathrm{d}_{\mathrm{B}, \mathrm{i}}^{3}}{\sum_{\mathrm{i}} \mathrm{d}_{\mathrm{B}, \mathrm{i}}^{2}}$

Sampling is representative when the mean Sauter diameter is no longer changed when measuring 10 new bubbles. This method leads to values of bubble measurements per stage ( $\mathrm{n}_{\text {bubble }}$ in Eq. (8)) from 100 to 150(about 600-750 measurements for the entire column). The results are represented as a bubble sizes distribution. The width of the class is determined from the statistical law given by Eq. (8).

$\mathcal{L}_{\mathrm{d}}=\frac{\mathrm{d}_{\mathrm{Bi}, \max }-\mathrm{d}_{\mathrm{Bi}, \text { min }}}{1+\frac{10}{3} \log \left(\mathrm{n}_{\text {bulles }}\right)}$

The results can be represented in terms of number or volume distributions. The number fraction of the considered class is calculated from the number of bubbles of this class and the total number of bubbles (Eq. (9)).

$\omega_{\mathrm{K}}=\frac{\mathrm{n}_{\text {bulles, } \mathrm{K}}}{\mathrm{n}_{\text {bulles }}}$

The volume fraction of the considered class is calculated from the ratio of the bubble volume of this class to the total bubble volume (Eq. (10)).

$\varsigma_{\mathrm{K}}=\frac{\mathrm{n}_{\text {bulles, } \mathrm{K}} \mathrm{V}_{\mathrm{B}, \mathrm{K}}}{\sum_{\mathrm{K}} \mathrm{n}_{\text {bulles, } \mathrm{K}} \mathrm{V}_{\mathrm{B}, \mathrm{K}}}$

\subsection{Measurement of the rising velocity}

The rising velocity of the bubbles is determined with a camera's shutter speed set to maximum (4000 frames per second). However, the camera can only record video at shutter speeds of 50 frames per second. External lighting is required to compensate for the poor lighting and to obtain clear outlines of the bubbles. The film is usually recorded over a period of one minute in order to obtain the maximum number of bubbles of different sizes. The VLC ${ }^{\circledR}$ software is used to process the videos. It allows for frame-by-frame tracking to follow an 


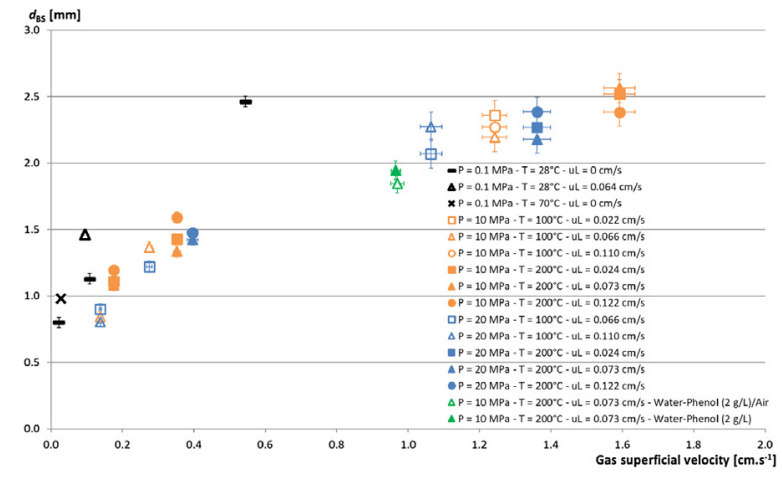

Fig. 2 - Evolution of the mean diameter of Sauter with $u_{G}$ for different $u_{L}$, temperature and pressure conditions.

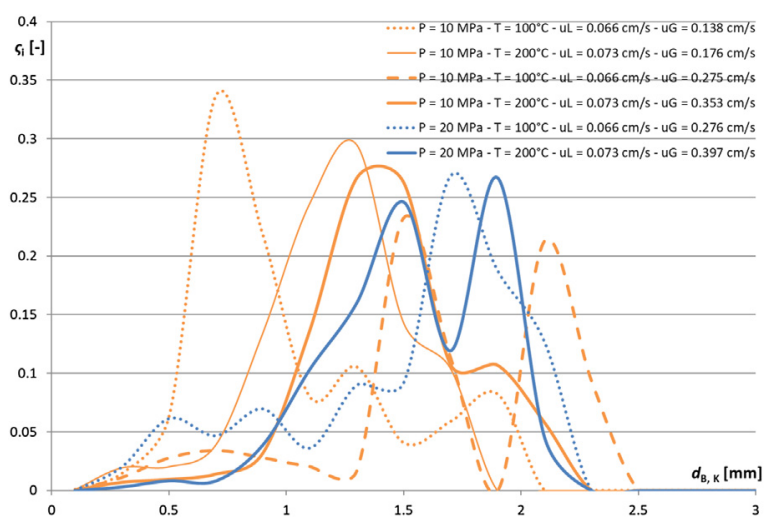

Fig. 3 - Influence of pressure and temperature on bubble size distribution.

ascending bubble. Once the chosen bubble has been located, screen captures are taken from the film and used with the GIMP $^{\circledR}$ software to determine its diameter and the distance travelled. The accuracy on a diameter is $85 \mu \mathrm{m}$ (relative error varying between 3.5 and $41.0 \%$ ). As previously, significant errors are obtained at low diameter: the uncertainty is higher than $20 \%$ for bubble diameters less than $0.3 \mathrm{~mm}$, between 8 and $20 \%$ for diameters less than $1 \mathrm{~mm}$ and becomes less than $5 \%$ for bubbles with a diameter higher than $1.7 \mathrm{~mm}$. The smallest diameter error has little influence on the measurement of the average velocity because these bubbles contribute little to its determination. The average velocity in volume and number of bubbles is given by Eq. (11).

$u_{B, m}=\left(\sum_{K} \omega_{K} u_{B, K}^{3}\right)^{1 / 3}$

\section{Results on the sapphire column}

\subsection{Bubble size and size distribution}

The results of the Sauter mean diameter and bubble size distribution are shown in Figs. 2 and 3, respectively. The coalescence rate is given in Supplementary material (Fig. S1).

\subsubsection{Influence of temperature and pressure}

Pressure and temperature have a small effect on the average bubble diameter compared to gas velocity (Fig. 2). Fig. 3 shows that at $10 \mathrm{MPa}$, the bubble size distributions indicate an increase of the size with an increase of the gas velocity at 100 ${ }^{\circ} \mathrm{C}\left(\mathrm{u}_{\mathrm{G}}\right.$ at 0.138 and $\left.0.275 \mathrm{~cm} \mathrm{~s}^{-1}\right)$ and at $200{ }^{\circ} \mathrm{C}\left(\mathrm{u}_{\mathrm{G}}\right.$ at 0.176 and

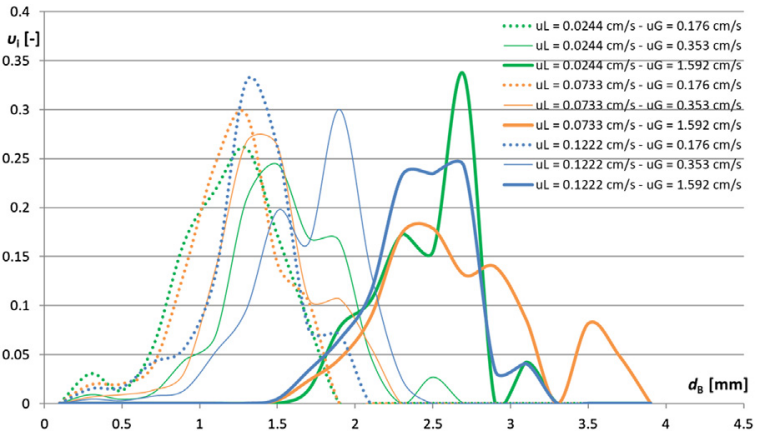

Fig. 4 - Bubbles size distributions at $P=10 \mathrm{MPa}$ and $\mathrm{T}=200$ ${ }^{\circ} \mathrm{C}$ for different gas and liquid flow conditions.

$0.353 \mathrm{~cm} \mathrm{~s}^{-1}$ ). Fig. S1 shows that the coalescence rate is lower at $200^{\circ} \mathrm{C}$ compared to $100^{\circ} \mathrm{C}$. At these flow rates, temperature could lead to a decrease in the rate of coalescence. In fact, the primary bubble is larger at $200{ }^{\circ} \mathrm{C}\left(\mathrm{u}_{\mathrm{G}}\right.$ larger) and therefore less likely to coalesce. Therefore, the effect on the distribution seems to be more related to the presence of a maximum of coalescence with $u_{G}$ rather than a temperature effect.

No significant difference was observed on the bubble size distributions at $1 \mathrm{MPa}$ and for $\mathrm{u}_{\mathrm{G}}>1 \mathrm{~cm} \mathrm{~s}^{-1}$. Fig. 3 shows that the influence of temperature is not predominant at 20 MPa since the distributions are substantially identical at both temperatures, although the gas velocity is higher at $200^{\circ} \mathrm{C}$. At higher gas velocity and $20 \mathrm{MPa}$, a higher proportion of small bubbles is observed at $200^{\circ} \mathrm{C}$ compared with $100^{\circ} \mathrm{C}$. Temperature seems to influence the primary bubble, smaller at $200^{\circ} \mathrm{C}$ $(1.6 \mathrm{~mm})$ than at $100{ }^{\circ} \mathrm{C}(1.7 \mathrm{~mm})$, despite the increase in $\mathrm{u}_{\mathrm{G}}$. The coalescence rate (Fig. S1) is higher at $200{ }^{\circ} \mathrm{C}$ compared to $100^{\circ} \mathrm{C}$, which is related to the smaller bubbles and the increase in $u_{G}$. Therefore, temperature has little effect on the coalescence rate. To conclude, the temperature tends to decrease the diameter of the primary bubble at high $\mathrm{u}_{\mathrm{G}}$ but has no effect on the coalescence. At low $\mathrm{u}_{\mathrm{G}}$, this effect is not observed, probably because the diameter is small at the exit of the frit filter.

The diameters at the column outlet are smaller at $20 \mathrm{MPa}$ than at $10 \mathrm{MPa}$. Increasing pressure leads therefore to a reduction in the rate coalescence. The bubble size distributions at $100{ }^{\circ} \mathrm{C}$ show a higher proportion of small bubbles at $20 \mathrm{MPa}$ compared to $10 \mathrm{MPa}$, with similar average bubble proportions. For the other conditions, pressure increases the primary bubble diameter at the outlet of the sparger. This is in fact identical for each experiment $\left(100 / 200{ }^{\circ} \mathrm{C}\right)$, whereas $u_{G}$ is higher for the experiment at $10 \mathrm{MPa}$. This effect is observed at high $\mathrm{u}_{\mathrm{G}}$ $\left(>1 \mathrm{~cm} \mathrm{~s}^{-1}\right)$, at 100 and $200{ }^{\circ} \mathrm{C}$. However, this effect is limited to low $u_{G}$. The rate of coalescence does not dependent on pressure, resulting in higher coalescences at $10 \mathrm{MPa}$ by the effect of $u_{G}$ and $d_{B}$. The pressure has an influence at low gas velocity at $100{ }^{\circ} \mathrm{C}$ and leads to a decrease in the average diameter. Pressure also increases the diameter of the primary bubble at high $\mathrm{u}_{\mathrm{G}}$. The temperature leads to tightening the distribution via an effect on the primary bubble at high $\mathrm{u}_{\mathrm{G}}$. If the proportion of small bubbles increases with temperature, the average diameter is little affected because the proportion of large bubbles remains high. Under the conditions for the water/nitrogen system, the coalescence/breakage equilibrium governs the hydrodynamics of the column.

\subsubsection{Influence of gas and liquid superficial velocity}

At $200{ }^{\circ} \mathrm{C}$, the average bubble diameter is larger for high liquid flow rates (Fig. 4). When $\mathrm{u}_{\mathrm{G}}$ increases, the distribution is 


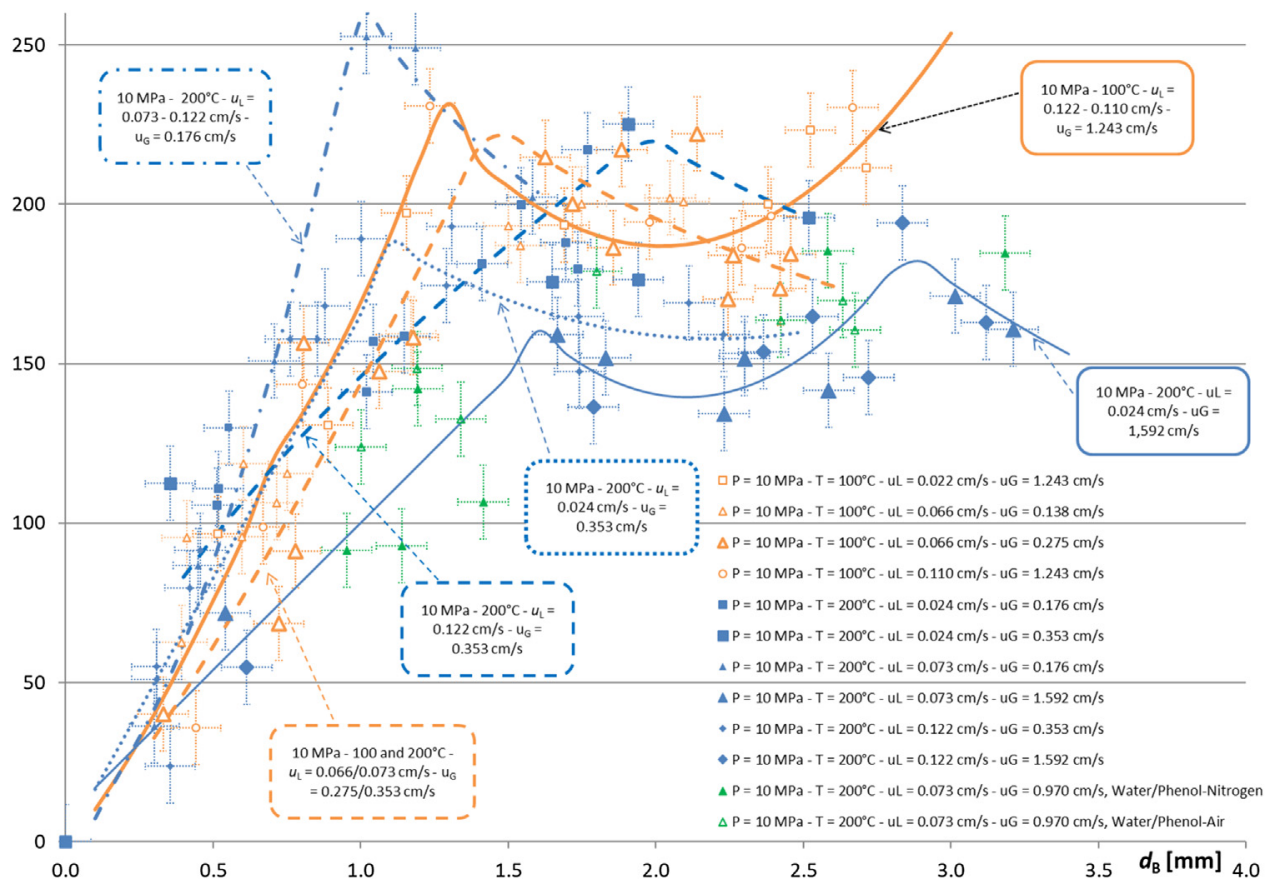

Fig. 5 - Evolution of the bubbles rise velocity according to their diameter.

shifted towards the larger diameters. This confirms the results of the literature concerning the effect of $\mathrm{u}_{\mathrm{G}}$ on the diameter of bubbles in a homogeneous regime. $u_{L}$ has an effect at lower $u_{G}$. Fig. 4 shows that the size distribution is narrower at intermediate liquid flows. At the lowest gas velocities, the distributions at the lowest liquid flow rates are identical. As $\mathrm{u}_{\mathrm{G}}$ increases, the low flow liquid delivery is shifted towards larger diameters. The distribution at the highest liquid flow rate is also shifted towards the larger diameters. At the largest $u_{G}$, the distributions are different but lead to identical average diameters. This indicates that $u_{L}$ has no influence for these high $u_{G}$. Therefore at $10 \mathrm{MPa}$ the effect of $\mathrm{u}_{\mathrm{L}}$ is limited to low gas velocities, as the effect of $u_{L}$ at $20 \mathrm{MPa}$ at 100 and $200{ }^{\circ} \mathrm{C}$ for $u_{G}>1$ $\mathrm{cm} \mathrm{s}^{-1}$. This confirms the results of the literature concerning the effect of the gas surface velocity on the bubble diameter in the homogeneous regime (Table 1)

An increase in the average diameter is observed when the bubbles rise in the column, regardless of the operating conditions, indicating coalescence phenomena (Supplementary material, Fig. S2). For the last two stages, the diameter along the vertical axis is constant. At $10 \mathrm{MPa}$ and $200{ }^{\circ} \mathrm{C}$, for the largest $\mathrm{u}_{\mathrm{G}}$, the influence of $\mathrm{u}_{\mathrm{L}}$ is not significant. For the other two values of $u_{G}$, the gap between the different mean diameters increases along the column, indicating an effect of $u_{L}$ on coalescence. This may be related to an increase in collision frequency or to turbulency. Finally, Fig. S2 shows that $u_{G}$ influences the primary bubble diameter. The diameter measured at the outlet of the porous material (first stage) increases with $u_{G}$. Moreover, the rate of coalescence increases with $u_{G}$, for all pressure and temperature conditions. $u_{\mathrm{L}}$ generally has no influence on the coalescence rate. In all cases, the average diameters obtained at the column outlet are identical. This indicates that the average diameter obtained at the column outlet does not depend on the primary bubble but rather on the coalescence/breakage balance.

\subsubsection{Influence of superficial tension}

In the water-phenol $\left(2 \mathrm{~g} \mathrm{~L}^{-1}\right) /$ nitrogen system at $10 \mathrm{MPa}$ and $200^{\circ} \mathrm{C}$, the influence of surface tension is limited because this parameter decreases slightly (water/nitrogen system: $41.2 \mathrm{mN}$ $\mathrm{m}^{-1}$, water-phenol / nitrogen system: $40.6 \mathrm{mN} \mathrm{m}^{-1}$ ). However, a slight decrease in the average diameter is observed and an effect on the primary bubble leading to smaller bubbles, with a higher coalescence rate in the column. The difference is both at the porous outlet and at the column head. These results agree with the influence of surface tension on the diameter of the primary bubble, on the rate of drainage of the film and on the breaking described in the introduction. Coalescence is also observed in the case of phenol solutions, the bubbles leaving the column being larger than those leaving the sparger. Since the collision frequency is much higher in the case of phenol, considering the number of bubbles, this indicates a decrease in the coalescence rate. The surface tension of water at $240^{\circ} \mathrm{C}$ is lower than that of phenol at $2 \mathrm{~g} \mathrm{~L}^{-1}$. Therefore, decrease in the primary bubble and the coalescence rate observed for phenol solutions is more related to an inhibitory effect of phenol coalescence.

\subsection{Bubble rise velocity}

The bubble rise velocity as a function of their diameter is shown in Fig. 5 (10 MPa). Temperature has little effect. The main influencing parameters are $u_{L}$ and $u_{G}$. The curves in Fig. 5 present a maximum whose position varies according to $\mathrm{u}_{\mathrm{L}}$ and $\mathrm{u}_{\mathrm{G}}$, for bubble diameters between 1 and $2 \mathrm{~mm}$. This type of profile is also observed by other authors, under pressure (Lin et al., 1998) and in atmospheric conditions. The bubble rise velocity for bubbles with a diameter higher than $1 \mathrm{~mm}$ tends to decrease with temperature (Kulkarni and Joshi, 2005). This may explain the lower bubble velocity observed at high pressures and temperatures compared to the final rising velocity under ambient conditions.

At $200{ }^{\circ} \mathrm{C}$ and for $\mathrm{u}_{\mathrm{L}}$ between 0.073 and $0.122 \mathrm{~cm} \mathrm{~s}^{-1}$, the higher $\mathrm{u}_{\mathrm{G}}$, the lower the bubble rise velocity is. This is explained by an increase in the volume of gas in the column (Glasscock and Rochelle, 1989). As $\mathrm{u}_{\mathrm{G}}$ increases, the maximum is shifted towards large diameters. $u_{\mathrm{L}}$ has an effect at low gas velocity only $\left(\mathrm{u}_{\mathrm{G}}<0.4 \mathrm{~cm} \mathrm{~s}^{-1}\right)$. An increase in $\mathrm{u}_{\mathrm{L}}$ leads to a 
shift from the maximum to smaller diameters. This indicates that a small diameter bubble is accelerated as $u_{\mathrm{L}}$ increases. At the highest gas velocity, no $u_{L}$ effect is observed. This seems to indicate that the effect of $u_{\mathrm{L}}$ depends on the relative order of magnitude of $u_{L}$ and $u_{G}$. The velocity of the bubbles can be identical when these two parameters are low, at low sliding velocity $u_{G}+u_{L}$, as suggested by the identical velocity of the bubbles for different $u_{G}$ and $u_{L}$ but at identical $u_{G}+u_{L}$, observed for experiments at 100 and $200{ }^{\circ} \mathrm{C}$. At $100{ }^{\circ} \mathrm{C}$ the same effects are observed at low $u_{G}$. The only difference comes from high gas flow experiments for which the bubble velocity is much higher than at $200^{\circ} \mathrm{C}$. This effect results from a higher coalescence rate for these experiments, inducing an increase in the diameter of the bubbles but also a significant decrease in their number.

At $20 \mathrm{MPa}$, the same effects of $\mathrm{u}_{\mathrm{G}}$ and $\mathrm{u}_{\mathrm{L}}$ are described. The influence of temperature is always negligible, especially at low gas flow. The maximum is observed earlier at 100 ${ }^{\circ} \mathrm{C}$ than at $200{ }^{\circ} \mathrm{C}$. This can be attributed to a weaker $\mathrm{u}_{\mathrm{G}}$ effect at $100{ }^{\circ} \mathrm{C}$. At high gas velocity, no visible effect of pressure is observed. The difference in rising velocity observed at large diameters is probably linked to an $\mathrm{u}_{\mathrm{G}}$ effect. The major difference is observed at $200{ }^{\circ} \mathrm{C}$ for large $u_{\mathrm{L}}$ and intermediate gas flow rates. Under these conditions, the maximum is higher for handling at $20 \mathrm{MPa}$ and the velocity is higher for identical diameters. Therefore, the pressure has a slight effect of reducing the diameter. The difference comes from smaller diameters at $20 \mathrm{MPa}$ : bubbles larger than $1.5 \mathrm{~mm}$ are more likely to be surrounded by bubbles of smaller diameters. These bubbles have a smaller contribution to the swarm effect.

From these experimental results, it is possible to calculate the rising velocity of each class of bubbles and therefore the average velocity in volume and number of bubbles (Eq. 11). Fig. S3 (Supplementary material) shows an increase in the average velocity of the bubbles with $u_{G}$ in the range $0-1 \mathrm{~cm} \mathrm{~s}^{-1}$, mainly because the mean diameter also increases with $u_{G}$. The effect of the bubble diameter is preponderant over the swarm effects in these conditions. At the highest values of $\mathrm{u}_{\mathrm{G}}\left(>1 \mathrm{~cm} \mathrm{~s}^{-1}\right)$, a decrease in mean velocity is observed with $\mathrm{u}_{\mathrm{G}}$. Since the increase in bubble diameter with $\mathrm{u}_{\mathrm{G}}$ is more limited at low gas velocity, swarm effects are preponderant, in the zone of decrease of the curve $u_{B, i}=f\left(d_{B, i}\right)$. At low $u_{G}$ $\left(<0.28 \mathrm{~cm} \mathrm{~s}^{-1}\right)$, a significant effect of $u_{\mathrm{L}}$ is observed, increasing the average velocity. This is consistent with the small bubble acceleration effect noted before. The effect is also visible on average velocity. Under these conditions, the mean diameter is located before the maximum of the curve $u_{B, i}=f\left(d_{B, i}\right)$. As $\mathrm{u}_{\mathrm{G}}$ increases, the effect of $\mathrm{u}_{\mathrm{L}}$ becomes weaker and is mostly limited to lower values. This is consistent with the lack of effects of $u_{L}$ on bubble velocity described previously. The overall effect is therefore related to the bubble diameter, higher at high velocity. This high value compensates for the effect of $u_{L}$. Therefore, pressure generally does not seem to have a major effect on velocities and diameters.

In the case of phenol solutions, the rising velocity is slower. This effect is related to the smaller mean diameter combined with swarm effects (high $\mathrm{u}_{\mathrm{G}}$ ). The average velocities are substantially identical in inert and reactive systems, due to identical average diameter and velocities.

In conclusion, the average bubbles rise velocity depends on the position of the maximum of the curve $u_{B, i}=f\left(d_{B, i}\right)$ and on the position of the average diameter with respect to this maximum.

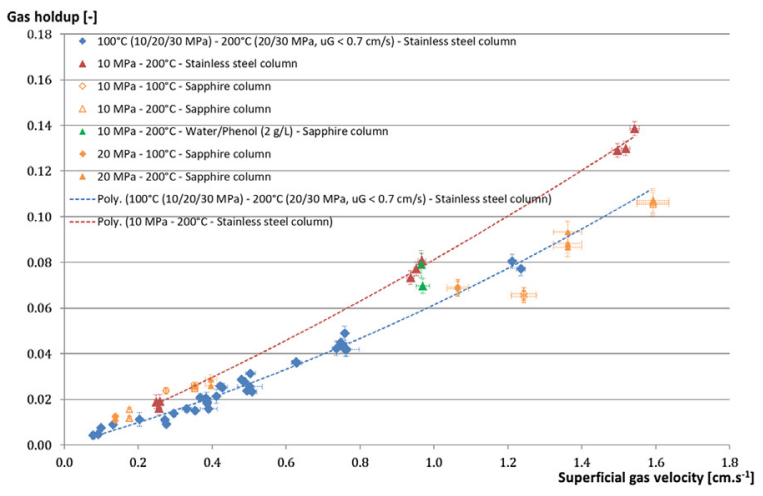

Fig. 6 - Evolution of gas hold up with $u_{G}$ for both columns.

\section{Study of scale effects: comparison of the results obtained with the two columns}

Bubble diameters and rise velocities are not accessible in the stainless-steel column. A more macroscopic parameter, the gas holdup, will be used to compare the results in the two columns. For the stainless-steel column, the determination of the gas holdup and description of the results has already been published in Leonard et al. (2019). The gas holdup depends on $\mathrm{u}_{\mathrm{G}}$ and bubble mean rise velocity in volume and number of bubbles (Eq. 12).

$\varepsilon_{\mathrm{G}}=\frac{\mathrm{u}_{\mathrm{G}}}{\mathrm{u}_{\mathrm{B}, \mathrm{m}}}$

The accuracy on the gas hold up measurement depends on the conditions of pressure, temperature and flowrate, and varies between $3.9 \%$ and $8.5 \%$.

\subsection{Comparison of results for the water / nitrogen system}

Fig. 6 shows the results of gas hold up measurements in the two columns. The experimental points obtained in the sapphire column indicate that the pressure, the temperature, and $\mathrm{u}_{\mathrm{L}}$ have no influence on the gas hold up, for all $\mathrm{u}_{\mathrm{G}}$ values.

At $100{ }^{\circ} \mathrm{C}$ and for $\mathrm{u}_{\mathrm{G}}<0.5 \mathrm{~cm} \mathrm{~s}^{-1}$, gas hold up is higher in the sapphire column than in the stainless steel column. The literature indicates that a decrease in column diameter leads to an increase in gas hold up (Ruzicka et al., 2001). The effect is mainly attributed to a decrease in the bubble rise velocity due to wall effects ora reduction of the bubble diameter. In the presence of a high density of bubbles with a small column diameter, the opposite effect can be considered: an increase in the bubble diameter resulting from a higher coalescence rate. This effect would increase the mean bubble rise velocity. Indeed, at these $u_{G}$, the mean bubble diameter is located before the maximum of the curves (Fig. 5). Therefore, this effect is not preponderant, and the bubble diameters are identical in the two columns. In this case, the column diameter variation leads to a velocity effect.

Fig. 6 shows that for large $u_{G}\left(>1 \mathrm{~cm} \mathrm{~s}^{-1}\right)$, the gas hold up in the two columns becomes identical, like the average bubble rising velocity. For each column, these velocities depend on the physico-chemical properties of the gas and the liquid and on the bubble diameters. If the wall effects are identical in both columns, it is therefore possible to scale up the bubble diameters from one column to another. 
It can be deduced that for $\mathrm{u}_{\mathrm{G}}<0,5 \mathrm{~cm} \mathrm{~s}^{-1}$, the average bubble rise velocity in the stainless-steel column is higher than in the sapphire column. Wall effects can be considered with a higher density of bubbles inducing more swarm effects. In the case of the stainless-steel column, a decrease in the bubble rise velocity is observed when $u_{G}$ increases. This indicates some effects that may slow down the bubbles as they rise, which can be swarm or wall effects. These two effects appear when the density of bubbles increases and/or when they become larger. In the sapphire column, wall and swarm effects are already present at the lowest $\mathrm{u}_{\mathrm{G}}$. Moreover, the decrease in average rising velocity with $\mathrm{u}_{\mathrm{G}}$, for large $\mathrm{u}_{\mathrm{G}}$ values, also suggests the presence of swarm effects. Identical rising velocity suggest similar swarm and wall effects. Under these conditions, it is possible to carry out the assumption of constant diameter from each column at $10 \mathrm{MPa} / 100{ }^{\circ} \mathrm{C}$ and $20 \mathrm{MPa} /$ $100-200^{\circ} \mathrm{C}$, which is consistent with some results reported in literature (Whalley and Hewitt, 1978; Kulkarni and Joshi, 2005).

The water / nitrogen system $\left(10 \mathrm{MPa}, 200^{\circ} \mathrm{C}\right)$ behaves differently in the stainless-steel column. Fig. 6 indicates that the gas hold up are identical at low $\mathrm{u}_{\mathrm{G}}$ but considerably higher in the stainless-steel column at the highest gas velocities. Moreover, the experiments at $10 \mathrm{MPa} / 200{ }^{\circ} \mathrm{C}$ in the sapphire column do not show any effect of the temperature, suggesting that the effect of evaporation observed in the stainless-steel column does not appear in the sapphire column. Indeed, in the stainless-steel column a significant effect of the saturation of the gas with water vapor was observed at low pressure (10 $\mathrm{MPa})$ and high temperatures $\left(200{ }^{\circ} \mathrm{C}\right)$. This result is consistent with (Leonard et al., 2019). It seems obvious that the time available to the gas for the transfer to the liquid is higher in the stainless-steel column. If the mass transfer coefficient and the interfacial area are close in the two columns, the quantity evaporated is higher in a larger column. Fig. S4 (Supplementary material) shows the evolution of the gas hold up in the sapphire column using $\mathrm{u}_{\mathrm{G}}$ (low saturation) and of the gas hold up in the stainless steel column using $\mathrm{u}_{\mathrm{G}}$,sat (significant saturation). The evolutions are identical indicating negligible saturation in the sapphire column. However, under these conditions, the low $\mathrm{u}_{\mathrm{G}}$ points $\left(<0.5 \mathrm{~cm} \mathrm{~s}^{-1}\right)$ are still not aligned. This is consistent with low gas saturation for the $10 \mathrm{MPa} / 100$ ${ }^{\circ} \mathrm{C}$ and $20 \mathrm{MPa} / 100-200{ }^{\circ} \mathrm{C}$ experiments in both columns. The points at $10 \mathrm{MPa}$ and $200{ }^{\circ} \mathrm{C}$ in the stainless-steel column are consistent with the others, indicating that the wall effect on the bubble rise velocity described previously explains the differences in gas hold up for all the points obtained at $\mathrm{u}_{\mathrm{G}}<0.5$ $\mathrm{cm} \mathrm{s}^{-1}$. Therefore, it is possible to scale up the diameters measured in the sapphire column to the stainless-steel column, if $\mathrm{u}_{\mathrm{G}}$ is used at saturation when calculating for the stainlesssteel column. The bubble diameter does not depend on the pressure or the temperature for high $\mathrm{u}_{\mathrm{G}}$.

In the absence of evaporation in the sapphire column, the effects of temperature on the primary bubble, the coalescence rate, the average bubble diameter, the bubble rise velocity, and the average velocity discussed previously are validated. On the other hand, a simple increase in $\mathrm{u}_{\mathrm{G}}$ does not explain the increase in gas hold up in the case of experiments in the stainless-steel column at $10 \mathrm{MPa}$ and $240{ }^{\circ} \mathrm{C}$, with an effect depending on $\mathrm{u}_{\mathrm{L}}$. For these experiments, it is possible to carry out the hypothesis of an increase in the bubble diameter, as for the points at $10 \mathrm{MPa}$ and $200{ }^{\circ} \mathrm{C}$ and to assume that the increase in gas hold up is linked to wall effects or to the proportions of gas and liquid. Under these conditions, the scale up of the diameter from one column to another for these con- ditions is also carried out from the diameter regression as a function of $\mathrm{u}_{\mathrm{G}}$ under saturated conditions.

\subsection{Comparison of results in the water-phenol / nitrogen system}

The two experiments in the sapphire column show an effect of increasing gas hold up of the water-phenol system compared to the water / nitrogen system in the stainless-steel column. It has already been noticed that the effect of the presence of phenol (at $2 \mathrm{~g} \mathrm{~L}^{-1}$ ) tends to increase with $\mathrm{u}_{\mathrm{G}}$. These experiments confirm this tendency to higher $\mathrm{u}_{\mathrm{G}}$. The study in the sapphire column confirms that the effect of the presence of phenol induces a decrease in the diameter of the primary bubble and the average diameter of the bubbles. The enhancing effect with $u_{G}$ may be related to the competitive effects of $u_{G}$ and surface tension. The primary bubble is in fact twice as large at $\mu_{G}>1 \mathrm{~cm} \mathrm{~s}^{-1}$ than in the range $0.2-0.6 \mathrm{~cm} \mathrm{~s}^{-1}$. Since the measurements in the two columns agree, it is possible to scale up the diameter measured in the sapphire column to the stainless-steel column.

\section{Correlation for scale up and design}

All the results presented in the previous sections make it possible to evaluate the influence of different parameters. In this part, the different scale up procedures of the diameters and rise velocities are presented. They can be used, for example, for determining the interfacial area in a column to be designed.

\subsection{Scale up of the diameters measured in the sapphire column to the stainless-steel column}

As the diameters are not readily available in the stainless-steel column, their determination is performed from the measurements made in the sapphire column, as explained previously. The criteria and calculations for scale up should consider the discussion in Part IV, considering the effect of $\mathrm{u}_{\mathrm{L}}$ at low $\mathrm{u}_{\mathrm{G}}$ at $10 \mathrm{MPa}$ and at $200{ }^{\circ} \mathrm{C}$ and $240{ }^{\circ} \mathrm{C}$. For these temperatures, no decrease in the bubble diameter is considered, the increase in gas hold up at low $u_{\mathrm{L}}$ being considered as an effect of the $\mathrm{u}_{\mathrm{G}} / \mathrm{u}_{\mathrm{L}}$ ratio. Pressure has no effect on bubble diameter. The 20 MPa data from the sapphire column is used for scaling up to 30 $\mathrm{MPa}$ in the stainless-steel column. The diameters are scaled up from the evolution of the curve $d_{B}=f\left(u_{G}\right)$ for each temperature and $u_{L}$. The scale up for the water-phenol system is more complex because an effect of temperature and composition is observed. In the sapphire column, and by analogy with the results obtained in clear water, no effect of pressure and temperature is considered. The absence of pressure effect is indeed observed at $30 \mathrm{~g} \mathrm{~L}^{-1}$ in the stainless-steel column (Leonard et al., 2019). No effect of $u_{L}$ is considered in the sapphire column due to a marginal effect (less than $5 \%$ deviation) on bubble diameter. Only $u_{G}$ has an influence. In the case of 2 $\mathrm{g} \mathrm{L}^{-1}$ solutions, only one point is available in the sapphire column. To get values at other $\mathrm{u}_{\mathrm{G}}$, the results at $30 \mathrm{~g} \mathrm{~L}^{-1}$ are used. The effect of $u_{G}$ has been explained to be the same for clear water and aqueous solutions of phenol at $30 \mathrm{~g} \mathrm{~L}^{-1}$ (public gas holdup). Under these conditions, for a given $\mathrm{u}_{\mathrm{G}}$, the diameter ratio is also constant, as shown in Eqs. (13) and (14).

$\mathcal{R}_{\mathrm{B}}=\frac{\mathrm{d}_{\mathrm{B}}\left(\mathrm{u}_{\mathrm{G} 1}, \text { water }\right)}{\mathrm{d}_{\mathrm{B}}\left(\mathrm{u}_{\mathrm{G} 2}, \text { water }\right)}=\frac{\mathrm{d}_{\mathrm{B}}\left(\mathrm{u}_{\mathrm{G} 1}, \text { water }- \text { phenol }\right)}{\mathrm{d}_{\mathrm{B}}\left(\mathrm{u}_{\mathrm{G} 2}, \mathrm{E}, \text { water }- \text { phenol }\right)}$ 


$$
\Rightarrow \frac{\mathrm{d}_{\mathrm{B}}\left(\mathrm{u}_{\mathrm{G} 1}, \text { water }\right)}{\mathrm{d}_{\mathrm{B}}\left(\mathrm{u}_{\mathrm{G} 1}, \text { water }- \text { phenol }\right)}=\frac{\mathrm{d}_{\mathrm{B}}\left(\mathrm{u}_{\mathrm{G} 2}, \text { water }\right)}{\mathrm{d}_{\mathrm{B}}\left(\mathrm{u}_{\mathrm{G} 2}, \text { water }- \text { phenol }\right)}
$$

The scale up to other superficial gas velocities (for solutions at 2 and $30 \mathrm{~g} \mathrm{~L}^{-1}$ ) is therefore carried out from a reference measurement (at $\mathrm{u}_{\mathrm{G}}=0.965 \mathrm{~cm} \mathrm{~s}^{-1}$ ). The diameter in water is easily scaled up from the curve $d_{B}=f\left(u_{G}\right)$. A measurement at 2 and $30 \mathrm{~g} \mathrm{~L}^{-1}$ is available. The calculation at the other $\mathrm{u}_{\mathrm{G}}$ is then carried out from the diameter measured in water and using Eq. 14.

To obtain the diameters at $10 \mathrm{~g} \mathrm{~L}^{-1}$, it is necessary to study the effect of phenol concentration on the bubble diameter. The influence of the mixture surface tension on the bubble diameter is shown in Fig. S5 (Supplementary material). The surface tensions are obtained by extrapolation of direct measurements of surface tensions, as a function of temperature and $\mathrm{x}_{\mathrm{w}}$ (Leonard et al., 2018). It is preferable to use surface tensions in unsaturated conditions for two reasons. The first is that the main effect of the presence of phenol is obtained on the primary bubble. The gas is then not completely saturated at the entrance of the reactor. The second is that the gas saturation rate is low in the sapphire column.

Extrapolation of these data to $38.2 \mathrm{mN}^{-1} \mathrm{~m}^{-1}$ (surface tension at $200^{\circ} \mathrm{C}$ and $10 \mathrm{~g} \mathrm{~L}^{-1}$ ) enables the calculation of the diameters at each $\mathrm{u}_{\mathrm{G}}$ for the solution at $10 \mathrm{~g} \mathrm{~L}^{-1}$. The data in the sapphire column at $200{ }^{\circ} \mathrm{C}$ for phenol solutions (at various concentrations) allow direct extrapolation to the stainless-steel column for tests at $200{ }^{\circ} \mathrm{C}$. The extrapolation is carried out from the curves $d_{B}=f\left(u_{G}\right)$ using $u_{G}$ under saturated conditions for the stainless-steel column. An effect of temperature between 200 and $240^{\circ} \mathrm{C}$ for systems operating with phenol was observed on gas hold up in the stainless-steel column. To obtain diameters at these temperatures, a correlation of the diameter must be determined. For each phenol concentration, the calculations show that it is possible to directly correlate the gas hold up, the average rise velocity and the average bubble diameter (in the stainless-steel column) by a power law (Eq. (15)).

$\frac{\mathrm{d}_{\mathrm{BS}}^{2}}{\mathrm{u}_{\mathrm{B}, \mathrm{m}}}=\complement_{1} \varepsilon_{\mathrm{G}} \mathrm{C}_{2}$

$C_{1}$ and $C_{2}$ vary with phenol concentration. The plots of Eq. 15 for water and 2, 10, and $30 \mathrm{~g} \mathrm{~L}^{-1}$ systems validate this equation under all conditions (Fig. S5). Therefore, it can be used to determine unknown diameters at each concentration.

\subsection{Correlation of bubble diameter}

Considering the discussions of part IV, the bubble diameter depends mainly on $u_{G}$ at saturation, on the phenol concentration (and hence surface tension) and on the temperature between 200 and $240{ }^{\circ} \mathrm{C}$ for phenol solutions. No effect of $\mathrm{u}_{\mathrm{L}}$ will be considered. The column diameter has no effect. As the presence of phenol induces an inhibitory effect of coalescence, considering the surface tension as a parameter will not give good results. Instead, the phenol mass fraction should be used. For the effect of temperature, the surface tension, viscosity and gas and liquid densities and the gravity constant should be considered. Therefore 8 parameters are necessary. Buckingham's theorem indicates that 5 dimensionless numbers are necessary to obtain the correlation. These numbers are the Eötvös number, the Tadaki number $\left(\mathrm{Mo}^{0.23}\right)$, the density ratio $(\kappa)$, the phenol mass fraction $\left(\mathrm{x}_{\mathrm{W}}\right)$ and a number dependent on $\mathrm{u}_{\mathrm{G} \text {,sat. }}$.
Table 2 - Constants for the correlation of the bubble diameter.

Parameter

However, it is not possible to define a dimensionless number involving $\mathrm{u}_{\mathrm{G}}$ at saturation without inducing strong deviations linked to an additional parameter, which does not appear in the list of parameters having an influence. Calculations show that the number of Eötvös is correlated with the number of Tadaki, Morton and $\mathrm{u}_{\mathrm{G}, \mathrm{sat}}$. Moreover, the influence of the mass fraction of phenol is difficult to extrapolate to 0 without inducing strong deviations for the water/nitrogen system. This is to be compared with Eq. 15, which presented strong deviations for the water-nitrogen system at high gas hold up. Under these conditions, it is difficult to obtain a general correlation for the number of Eötvös. A simpler correlation of the diameter (Eq. (16)), representing well the experimental data was however found, involving the mass fraction of phenol and $\mathrm{u}_{\mathrm{G}, \mathrm{sat}}$.

$d_{B S}=\left[\complement_{3} \ln \left(u_{G, s a t}\right)+\complement_{4}\right]\left(1+x_{w, P h}\right)^{C_{5}}$

The constants are given in Table 2. Eq. 16 leads to an average uncertainty on the predicted values of 3.4\% (5.7\% for the waterphenol system and $2.8 \%$ for water). The maximum deviation is $17.3 \%$ with only 4 points (out of 131 ) predicted with more than $9.3 \%$ uncertainty, all being at $u_{\mathrm{G}, \mathrm{sat}}<0.3 \mathrm{~cm} \mathrm{~s}^{-1}$.

\subsection{Correlation for bubble rise velocity}

The average bubble rise velocity depends mainly on the bubble diameter $\mathrm{s}$, the column diameter, and the phenol mass fraction. Since the bubble diameter $\mathrm{s}$ depends on $\mathrm{u}_{\mathrm{G}, \mathrm{sat}}$, the influence of this parameter can be indirectly taken into account with the diameter.

It may be interesting to correlate the bubble rise velocity with the help of a Weber bubbles number which will consider the influence of temperature in the case of aqueous solutions of phenol. Dimensional analysis shows that 5 dimensionless numbers are required when considering gas and liquid densities, viscosity, gravity constant, bubble diameter, rising velocity, and surface tension. It is necessary to add the phenol mass fraction and the column diameter. Under these conditions 6 numbers are necessary. It is possible to select the bubble Reynolds, bubble Weber, density ratio $\kappa$, Tadaki number, phenol mass fraction and $d_{B S} / D_{C}$ ratio (Eq. (17)). The effect of the $u_{G} / u_{L}$ ratio is indirectly taken into account by the terms dependent on pressure, temperature and $u_{B, m}$.

$\mathrm{We} e_{\mathrm{B}}=\operatorname{Re}_{\mathrm{B}}{ }^{C_{1}} \mathrm{Ta} a^{\complement_{2}} \kappa^{\complement_{3}}\left(\frac{d_{B S}}{D_{C}}\right)^{C_{4}}\left(1+x_{w, P h}\right)^{C_{5}}$

The constants of Eq. (17) are given in Table 3.

The plotting of the results obtained from correlation (Eq. (17)) and experimental results indicates that the average uncertainty is $2.3 \%$. The maximum uncertainty is $6.8 \%$. The comparison between the predicted bubble rise velocities with experimental ones is given in Fig. S6 (Supplementary material section). 
Table 3 - Constants for the correlation of the average rising velocity in the case of the stainless-steel column.

\section{Parameter}

Value

$\mathrm{C}_{1}$

2.018

2.621

$-1.399$

$-1.032$

$\complement_{5}$

The equation seems to predict an influence of pressure (via the difference in the densities of gas and liquid). In fact, it is possible to show that when the pressure increases between 10 and $30 \mathrm{MPa}$, the term $\Delta \rho^{0,217}$ varies by at most $3 \%$. The presence of this term therefore comes more from the influence of temperature on the densities.

\section{Conclusion}

The design of bubble columns under high pressure and temperature conditions is not well developed. Experimental results are proposed in this research to obtain accurate data on the evolution and behaviour of the bubbles in such reactor. Indeed, no valid correlations at high pressure and temperature conditions for bubble size and bubble size distribution can be found. Literature results indicate that three main factors should be considered: pressure, temperature and superficial velocities of gas and liquid. These parameters have been tested in two experimental columns: sapphire column and stainless-steel column.

Main results indicates that pressure and temperature have a small effect on the average bubble diameter compared to gas velocity. The effects on the bubble size distribution are related to the presence of a maximum of coalescence with $u_{G}$ rather than a temperature effect. The effect of $u_{G}$ is also observed on the primary bubble formation. However, the pressure could have an influence leading to a decrease in the average diameter. It also helps to increase the diameter of the primary bubble at high $\mathrm{u}_{\mathrm{G}}$. Moreover, for the water/nitrogen system, it is the coalescence/breakage equilibrium which governs the hydrodynamics of the column and especially the average diameter obtained at the column outlet. Concerning the presence of a pollutant (phenol in this study), the effect of reducing the primary bubble and the coalescence rate is more to an inhibitory effect of phenol coalescence.

The comparison between the two columns is based on the fact that the bubble diameters are identical in the two columns. In this case, the effect of the diameter of the column only leads to a velocity effect. Moreover, identical rising velocity suggest similar swarm and wall effects; it is therefore possible to scale up the bubble diameters from one column to another, if $\mathrm{u}_{\mathrm{G}}$ is used at saturation when calculating for the stainless-steel column.

Concerning the correlation for the bubbles diameter, it has been shown that the influence of the mass fraction of phenol is difficult to extrapolate to 0 without inducing strong deviations for the water/nitrogen system. Therefore, a simpler correlation of the diameter, representing well the experimental data is proposed, taking into account the mass fraction of phenol and $\mathrm{u}_{\mathrm{G}, \mathrm{sat}}$. Concerning the bubble size distribution, a correlation considering the bubble Reynolds, bubble Weber, density ratio $\kappa$, Tadaki number, phenol mass fraction and $d_{B S} / D_{c}$ ratio is proposed. These two correlations, validated under high pressure and temperature conditions, are an important basis

to derive for instance the interfacial area in a bubble column, and therefore volume necessary for the mass transfer of oxygen. The knowledge of this parameters is of high importance to be used for the industrial design of bubble column.

\section{Conflict of interests}

The authors declare that they have no known competing financial interests or personal relationships that could have appeared to influence the work reported in this paper.

\section{Appendix A. Supplementary data}

Supplementary material related to this article can be found, in the online version, at doi:https://doi.org/10. 1016/j.cherd.2021.07.003.

\section{References}

Behkish, A., Lemoine, R., Sehabiague, L., Oukaci, R., Morsi, B.I., 2007. Gas holdup and bubble size behavior in a large-scale slurry bubble column reactor operating with an organic liquid under elevated pressures and temperatures. Chem. Eng. J. 128 (2-3), 69-84.

Bouaifi, M., Hebrard, G., Bastoul, D., Roustan, M., 2001. A comparative study of gas hold-up, bubble size, interfacial area and mass transfer coefficients in stirred gas-liquid reactors and bubble columns. Chem. Eng. Process. Process Intensif. 40 (2), 97-111.

Brian, P.L.T., Hurley, J.F., Hasseltine, E.H., 1961. Penetration theory for gas absorption accompanied by a second order chemical reaction. AIChE J. 7, 226-231.

Dewes, I., Schumpe, A., 1997. Gas density effect on mass transfer in the slurry bubble column. Chem. Eng. Sci. 52 (21-22), 4105-4109.

Ferreira, A., Cardoso, P., Teixeira, J.A., Rocha, F., 2013. pH influence on oxygen mass transfer coefficient in a bubble column. Individual characterization of $\mathrm{k}_{\mathrm{L}}$ and a. Chem. Eng. Sci. 100 (0), 145-152

Friedel, L., 1979. Improved friction pressure drop correlations for horizontal and vertical Two- phase pipe flow. In: European Two-Phase Flow Group Meeting, Ispra, Italy, paper E2.

Fukuma, M., Muroyama, K., Yasunishi, A., 1987. Properties of bubbles swarm in a slurry bubble column. J. Chem. Eng. Jpn. 20 (1), 28-33.

García-Abuín, A., Gómez-Díaz, D., Navaza, J.M., Vidal-Tato, I., 2010. $\mathrm{CO}_{2}$ capture by aqueous solutions of glucosamine in a bubble column reactor. Chem. Eng. J. 162 (1), 37-42.

Glasscock, D.A., Rochelle, G.T., 1989. Numerical simulation of theories for gas absorption with chemical reaction. AIChE J. 35 (8), 1271-1281.

Hashemi, S., Macchi, A., Servio, P., 2009. Gas-liquid mass transfer in a slurry bubble column operated at gas hydrate forming conditions. Chem. Eng. Sci. 64 (16), 3709-3716.

Kang, Y., Cho, Y.J., Woo, K.J., Kim, K.I., Kim, S.D., 2000. Bubble properties and pressure fluctuations in pressurized bubble columns. Chem. Eng. Sci. 55 (2), 411-419.

Kantarci, N., Borak, F., Ulgen, K.O., 2005. Bubble column reactors. Process. Biochem. 40 (7), 2263-2283.

Kluytmans, J.H.J., Van Wachem, B.G.M., Kuster, B.F.M., Schouten, J.C., 2003. Mass transfer in sparged and stirred reactors: influence of carbon particles and electrolyte. Chem. Eng. Sci. 58 (20), 4719-4728.

Krishna, R., Ellenberger, J., 1996. Gas holdup in bubble column reactors operating in the churnturbulent flow regime. AIChE J 42 (9), 2627-2634.

Kulkarni, A.A., Joshi, J.B., 2005. Bubble formation and bubble rise velocity in gas-liquid systems: a review. Ind. Eng. Chem. Res. 44 (16), 5873-5931. 
Kumar, S., Munshi, P., Khanna, A., 2012a. High pressure experiments and simulations in cocurrent bubble columns. Procedia Eng. 42 (0), 842-853.

Kumar, S., Kumar, R.A., Munshi, P., Khanna, A., 2012b. Gas hold-up in three phase co-current bubble columns. Procedia Eng. 42 (0), 782-794.

Lau, R., Lee, P.H.V., Chen, T., 2012. Mass transfer studies in shallow bubble column reactors. Chem. Eng. Process. Process Intensif. 62 (0), 18-25.

Lefèvre, S., Ferrasse, J.H., Boutin, O., Sergent, M., Faucherand, R., Viand, A., 2011. Process optimisation using the combination of simulation and experimental design approach: application to wet air oxidation. Chem. Eng. Res. Des. 89, 1045-1055.

Leonard, C., Ferrasse, J.H., Boutin, O., Lefevre, S., Viand, A., 2018. Measurements and correlations for gas liquid surface tension at high pressure and high temperature. AIChE J. 64, 4110-4117.

Leonard, C., Ferrasse, J.H., Lefevre, S., Viand, A., Boutin, O., 2019. Gas hold up in bubble column at high pressure and high temperature. Chem. Eng. Sci. 200, 186-202.

Letzel, M.H., Schouten, J.C., Van den Bleek, C.M., Krishna, R., 1998. Effect of gas density on large-bubble holdup in bubble column reactors. AIChE J. 44 (10), 2333-2336.

Lin, T.-J., Fan, L.-S., 1999. Heat transfer and bubble characteristics from a nozzle in high pressure bubble columns. Chem. Eng. Sci. 54 (21), 4853-4859.

Lin, T.J., Tsuchiya, K., Fan, L.-S., 1998. Bubble flow characteristics in bubble columns at elevated pressure and temperature. AIChE J. 44 (3), 545-560

Lorenz, O., Schumpe, A., Ekambara, K., Joshi, J.B., 2005. Liquid phase axial mixing in bubble columns operated at high pressures. Chem. Eng. Sci. 60 (13), 3573-3586.

Majumder, S.K., Kundu, G., Mukherjee, D., 2006. Bubble size distribution and gas-liquid interfacial area in a modified downflow bubble column. Chem. Eng. J. 122 (1-2), 1-10.

Ohki, Y., Inoue, H., 1970. Longitudinal mixing of the liquid phase in bubble columns. Chem. Eng. Sci. 25 (1), 1-16.

Oyevaar, M.H., Bos, R., Westerterp, K.R., 1991. Interfacial areas and gas hold-ups in gas-liquid contactors at elevated pressures from 0.1 to 8.0 MPa. Chem. Eng. Sci. 46 (5-6), 1217-1231.

Pjontek, D., Parisien, V., Macchi, A., 2014. Bubble characteristics measured using a monofibre optical probe in a bubble column and freeboard region under high gas holdup conditions. Chem. Eng. Sci. 111 (0), 153-169.

Pohorecki, R., Moniuk, W., Zdrójkowski, A., Bielski, P., 2001. Hydrodynamics of a pilot plant bubble column under elevated temperature and pressure. Chem. Eng. Sci. 56 (3), 1167-1174.

Polli, M., Stanislao, M.D., Bagatin, R., Bakr, E.A., Masi, M., 2002. Bubble size distribution in the sparger region of bubble columns. Chem. Eng. Sci. 57 (1), 197-205.

Reilly, I.G., Scott, D.S., De Bruijn, T., Jain, A., Piskorz, J., 1986. A correlation for gas holdup in turbulent coalescing bubble columns. Can. J. Chem. Eng. 64 (5), 705-717.
Rollbusch, P., Bothe, M., Becker, M., Ludwig, M., Grünewald, M., Schlüter, M., Franke, R., 2015. Bubble columns operated under industrially relevant conditions - current understanding of design parameters. Chem. Eng. Sci. 126 (0), 660-678.

Ruzicka, M.C., Drahoš, J., Fialová, M., Thomas, N.H., 2001. Effect of bubble column dimensions on flow regime transition. Chem. Eng. Sci. 56 (21-22), 6117-6124.

Sangnimnuan, A., Prasad, G.N., Agnew, J.B., 1984. Gas hold-up and back mixing in a bubble column reactor under coal-hydroliquefaction conditions. Chem. Eng. Commun. 25 (1-6), 193-212.

Schäfer, R., Merten, C., Eigenberger, G., 2002. Bubble size distributions in a bubble column reactor under industrial conditions. Exp. Therm. Fluid Sci. 26 (6-7), 595-604.

Shah, Y.T., Kelkar, B.G., Godbole, S.P., Deckwer, W.D., 1982. Design parameters estimations for bubble column reactors. AIChE J. 28 (3), 353-379.

Simonnet, M., Gentric, C., Olmos, E., Midoux, N., 2007. Experimental determination of the drag coefficient in a swarm of bubbles. Chem. Eng. Sci. 62 (3), 858-866.

Soong, Y., Harke, F.W., Gamwo, I.K., Schehl, R.R., Zarochak, M.F., 1997. Hydrodynamic study in a slurry-bubble-column reactor. Catal. Today 35 (4), 427-434.

Tomiyama, A., Celata, G.P., Hosokawa, S., Yoshida, S., 2002. Terminal velocity of single bubbles in surface tension force dominant regime. Int. J. Multiph. Flow 28 (9), 1497-1519.

Wellek, R.M., Brunson, R.J., Law, F.H., 1978. Enhancement factors for gas absorption with $2^{\text {nd }}$ order irreversible chemical reaction. Can. J. Chem. Eng. 56, 181-186.

Whalley, P.B., Hewitt, G.F., 1978. The Correlation of Liquid Enyrainment Fraction and Entrainment Rate in Annular Two-Phase Flow. Rept. AERE-R9187. UKAEA, Harwell.

Wilkinson, P.M., Van Dierendonck, L.L., 1990. Pressure and gas density effects on bubble breakup and gas hold-up in bubble columns. Chem. Eng. Sci. 45 (8), 2309-2315.

Wilkinson, P.M., Spek, A.P., Van Dierendonck, L.L., 1992. Design parameters estimation for scale-up of high-pressure bubble columns. AIChE J. 38 (4), 544-554.

Wilkinson, P.M., Haringa, H., Van Dierendonck, L., 1994. Mass transfer and bubble size in a bubble column under pressure. Chem. Eng. Sci. 49 (9), 1417-1427.

Xue, J., Al-Dahhan, M.H., Dudukovic, M.P., Mudde, R.F., 2008. Bubble velocity, size, and interfacial area measurements in a bubble column by four-point optical probe. Aiche J. 54 (2), 350-363.

Yang, W., Wang, J., Jin, Y., 2001. Mass transfer characteristics of syngas components in slurry system at industrial conditions. Chem. Eng. Technol. 24 (6), 651-656.

Zahradník, J., Fialová, M., Růžička, M., Drahoš, J., Kaštánek, F., Thomas, N.H., 1997. Duality of the gas-liquid flow regimes in bubble column reactors. Chem. Eng. Sci. 52 (21-22), 3811-3826. 